\title{
Amores de Ovídio Livro segundo, Elegia décima
}

Daniel da Silva Moreira

\section{Introdução}

Os Amores são um conjunto de elegias eróticas, compostas provavelmente entre 23 e 14 a.C., e organizadas de modo a constituírem o panorama completo de uma história amorosa, em que se destaca a figura de Corina, pseudônimo literário dado por Ovídio (43 a.C. - 17 d.C.) à sua amada. Os modelos elegíacos helenísticos, e mesmo os de poetas latinos anteriores a Ovídio, fazem-se sempre presentes, embora o poeta saiba imprimir no texto sua marca pessoal. O poema que ora apresento em tradução em verso para o português é a décima elegia do segundo livro dos Amores, obra tida como a primeira que se publicou do poeta sulmonense. A elegia em questão ${ }^{1}$, escrita à feição de uma carta, trata de um lugar-comum muito freqüente na lírica amorosa ocidental - a indecisão do eulírico entre dois amores.

Texto latino proveniente de: OVIDE. Les Amours. Téxte établi et traduit par Henri Bornecque. Paris: Les Belles Lettres, 2005. p. 90-92. 
Tu mihi, tu certe, memini, Graecine, negabas Vno posse aliquem tempore amare duas.

Per te ego decipior, per te deprensus inermis, Ecce, duas uno tempore turpis amo.

Vtraque formosa est, operosae cultibus ambae;

Artibus in dubio est haec sit an illa prior.

Pulchrior hac illa est, haec est quoque pulchrior illa;

Et magis haec nobis et magis illa placet.

Errant ut uentis discordibus acta phaselos

Diuiduumque tenent alter et alter amor.

Quid geminas, Erycina, meos sine fine dolores?

Non erat in curas una puella satis?

Quid folia arboribus, quid pleno sidera caelo,

In freta collectas alta quid addis aquas?

Sed tamen hoc melius, quam si sine amore iacerem.

Hostibus eueniat uita seuera meis;

Hostibus eueniat uacuo dormire cubili

Et medio late ponere membra toro.

At mihi saeuus amor somnos abrumpat inertes,

Simque mei lecti non ego solus onus.

Me mea disperdat nullo prohibente puella

Si satis una potest; si minus una, duae.

Sufficiam; graciles, non sunt sine uiribus artus:

Pondere, non neruis corpora nostra carent.

Et lateri dabit in uires alimenta uoluptas;

Decepta est opera nulla puella mea;

Saepe ego lasciue consumpsi tempora noctis

Utilis et forti corpore mane fui.

Felix, quem Veneris certamina mutua rumpunt!

Di faciant leti causa sit ista mei!

Induat aduersis contraria pectora telis

Miles et aeternum sanguine nomen emat;

Quaerat auarus opes et, quae lassarit arando,

Aequora periuro naufragus ore bibat;

At mihi contingat Veneris languescere motu,

Cum moriar, medium soluar et inter opus,

Atque aliquis nostro lacrimans in funere dicat.

"Conueniens uitae mors fuit ista tuae." 
$\mathrm{Tu}, \mathrm{Grecino},{ }^{2}$ eu me lembro com certeza, tu negavas

Que alguém pudesse a um só tempo amar a duas.

Por ti fui enganado, por ti, pego desarmado,

E eis-me aqui! Torpe, a duas a um só tempo amo!

Ambas são formosas e esmeradas em seus cuidados

E não sei se esta ou aquela é a mais talentosa.

Esta é mais bela que aquela, que é também mais que esta;

E mais me agrada esta, e mais me agrada aquela!

Vago, como um batel levado por ventos contrários,

E dividido me detêm um e outro amor.

Por que, Ericina, ${ }^{3}$ duplicas meus tormentos sem fim?

Não bastava a aflição com uma só mulher?

Por que folhas às árvores e estrelas a um céu pleno

Juntas? Por que águas aos mares profundos lanças?

Mas isto ainda é melhor que se sem amor ficasse.

Aos meus inimigos caiba uma vida austera!

Aos inimigos caiba dormir em leito vazio

E esticar bastante os membros sobre uma cama!

A mim, que o amor feroz interrompa o sono inerte,

E que eu não seja o único peso em meu leito!

Que minha mulher me esgote, sem que ninguém impeça,

Se uma só basta, que uma seja, e se não, duas!

Suportarei; meus membros são magros, mas não sem forças;

De peso e não de nervos meu corpo carece;

E a volúpia dará forças e sustento aos meus flancos.

Nunca enganei mulher alguma nesta lida;

Por muitas vezes consumi toda a noite em lascívia,

E de manhã tinha o corpo forte e capaz.

Feliz o que morre na mútua batalha do Amor!

Que os deuses façam que assim seja a minha morte!

Que o soldado ofereça o peito aos dardos inimigos

E conquiste com seu sangue a glória eterna.

Que o avaro busque ao longe riquezas e, num naufrágio,

Beba dos mares com sua boca perjura.

Mas a mim caiba languescer no exercício de Vênus;

Quando morrer, que eu seja pego em meio à ação;

De modo que em meu funeral alguém diga chorando:

"Esta morte foi condizente à tua vida!" 


\section{Do poema e da tradução}

O poeta começa por uma imprecação contra Graecinus, seu amigo, por tê-lo feito crer que fosse impossível que alguém pudesse amar duas pessoas ao mesmo tempo. Ao colocar à prova a crença de seu amigo, constata ser ela falsa e acaba conduzido ao erro de amar duas mulheres, o que servirá de ponto de partida para o trecho da elegia em que ambas as amadas são comparadas sem que se chegue a uma decisão sobre qual delas escolher. Não encontrando solução para esse dilema, o eu-lírico invoca a deusa do amor, questionando o motivo de ela acrescentar mais um tormento à sua vida, que já seria suficientemente conturbada se amasse apenas uma pessoa. A partir do décimo quinto verso, o poema sofre uma mudança de tom inesperada e, em lugar de prosseguir com o relato de seu infortúnio, o poeta parece se conformar dizendo: "Sed tamen hoc melius, quam si sine amore iacerem" (verso 15, "Mas isto ainda é melhor que se sem amor ficasse", na presente tradução). Em seguida, o poeta passa a relatar suas qualidades de amante, chegando mesmo a ambicionar o esgotamento físico pelo exercício amoroso e a preferir, para sua satisfação, ter duas amantes. Por fim, o poeta deseja que a morte o encontre em meio ao ato sexual, de modo que em seu funeral possa ser dito: "Conueniens uitae mors fuit ista tuae" (verso 38, "Esta morte foi condizente à tua vida!", na presente tradução).

Ao traduzir esta elegia de Ovídio, optei por fazê-lo em verso, buscando assim recriar poeticamente em português o original latino. A escolha do tipo de verso empregado no texto em português foi, antes de tudo, influenciada pela leitura de três elegias dos Amores (I.5, II.4 e III.7) traduzidas por José Paulo Paes (Ovídio, 1997), que utilizou versos de quatorze e doze sílabas para recriar, respectivamente, os hexâmetros e pentâmetros do dístico elegíaco. O excelente resultado obtido por Paes foi capaz de me convencer de que tais versos da língua portuguesa são tão válidos para a tradução do dístico elegíaco quanto a alternativa mais comum, de se traduzir o 
hexâmetro por um verso de doze sílabas e o pentâmetro por um verso de dez sílabas. O verso de doze sílabas que utilizei para traduzir o pentâmetro procura, no mais das vezes, respeitar a cesura entre os hemistíquios, constituindo o que é conhecido como verso alexandrino. Contudo, abri mão da cesura quando percebi que sua presença prejudicaria a estrutura e a elegância do verso, usando neste caso o verso sem cesura, o simples verso de doze sílabas. A utilização de versos de medidas diferentes é uma tentativa de manter a claudicação do dístico elegíaco, característica marcante das elegias. Ainda em relação ao dístico, procurei preservar uma de suas qualidades, a de, no interior do poema, constituir-se como uma unidade completa e, de certo modo, isolada, em que o poeta normalmente conclui seu pensamento. Na presente tradução conservei essa característica em todos os dísticos, à exceção daqueles em que o próprio poeta subverte as regras, ocasiões em que o acompanhei.

Uma propriedade do texto de Ovídio - que o torna ainda mais acentuadamente poético - é a musicalidade do verso latino, dada pela alternância entre sílabas breves e longas. Entretanto, ao reconstruir o poema em português, não há como reproduzir em igualdade a duração da língua latina, por ser esta uma peculiaridade do latim que não passou ao português. Busquei compensar a perda do que há de mais musical na poesia latina - a já citada alternância entre sílabas breves e longas - com um recurso que julgo equivalente no âmbito do sistema versificatório românico, por ser o que há de mais musical na técnica do verso em português: a alternância rítmica entre sílabas átonas e tônicas, responsável por criar uma cadência bastante marcada.

Também merece destaque na elegia erótica ovidiana - e em especial na elegia em questão - o comedimento no uso da linguagem. O poeta trabalha todo o seu texto dentro de um jogo vocabular em que nenhuma alusão ao sexo é demasiadamente desvelada, todas são expressas através de metáforas ou de metonímias que permitam a multiplicidade de sentidos, preservando sempre um outro sentido além do sexual; um outro sentido, pode-se dizer, pudico. 
Na presente tradução procurei privilegiar a manutenção, sempre que possível, desse jogo de palavras, com o intuito de fazer com que o texto de Ovídio permanecesse aberto. Para tanto, lancei mão, em português, de vocábulos que, como os que o poeta emprega, estão relacionados intimamente ao campo semântico do trabalho, da atividade física, mas que guardam certa conotação sexual. É o que pode ser visto, por exemplo, em: "Et lateri dabit in uires alimenta uoluptas;/ Decepta est opera nulla puella mea" (Ovide, 2005, p. 92, versos 2526). Nesses versos, Ovídio faz uso de um termo pertencente ao campo semântico do trabalho (opera), empregando-o de modo a não aludir diretamente ao verdadeiro trabalho a que se refere. Na tradução empreguei o vocábulo lida, que mantém a equivalência com o latim opera e, sem um apelo à referência explícita, remete o leitor do poema, pelo contexto, ao ato sexual. O resultado pode ser conferido em: “E a volúpia dará forças e sustento aos meus flancos./Nunca enganei mulher alguma nesta lida" (versos 25-26 da presente tradução).

Ainda que nem de longe represente a totalidade das quase cinqüenta elegias dos Amores, a décima elegia de seu segundo livro dá uma pequena mostra da poesia amorosa de Ovídio, e faz um convite à leitura da obra desse poeta cuja importância e influência sobre a poesia ocidental sempre foram, não por mero acaso, constantes e profundas. 


\section{Referências:}

NÉRADAU, Jean-Pierre. Introduction. In: OVIDE. Les Amours. Texte établi et traduit par Henri Bornecque. Paris: Les Belles Letres, 2005.

OVIDE. Les Amours. Texte établi et traduit par Henri Bornecque. Paris: Les Belles Letres, 2005.

OVÍDIO. Poemas da Carne e do Exílio. Seleção, tradução e notas de José Paulo Paes. São Paulo: Companhia das Letras, 1997.

\section{Notas}

2 Grecino (Publius Pomponius Graecinus) é o amigo a quem Ovídio endereça 3 de suas Pônticas (obra que compreende as epístolas em forma de elegia escritas a partir do exílio). Numa das 3 epístolas, Ovídio congratula seu amigo por ter sido eleito cônsul.

3 Ericina é um dos epítetos de Vênus, dado em razão do templo que se levantou em sua homenagem aos pés do monte Érix, na Sicília. 